\title{
A Novel Electrochemical Method for Protionamide Determination Based on Its Interaction with Alizarin Red S
}

\author{
Weili Zhang, Xueliang Niu, Hua Zhang, Qingqing Jiang, and Pingping Zhang \\ Pharmacy College, Key Laboratory of Biomedical Engineering and Technology in Universities of Shandong, \\ Qilu Medical University, Zibo 255213, China \\ Correspondence should be addressed to Xueliang Niu; xueliangniu@163.com
}

Received 3 May 2015; Accepted 10 August 2015

Academic Editor: Adalgisa Rodrigues de Andrade

Copyright (C) 2015 Weili Zhang et al. This is an open access article distributed under the Creative Commons Attribution License, which permits unrestricted use, distribution, and reproduction in any medium, provided the original work is properly cited.

\begin{abstract}
The interaction of protionamide with alizarin red S (ARS) and its analytical application were carefully investigated in this contribution. The interaction conditions were carefully studied and optimized by cyclic voltammetry. Under the optimum conditions, the cyclic voltammetry curve of ARS showed an oxidation peak with the peak potential of $0.57 \mathrm{~V}$. After the addition of protionamide to the ARS solution, the peak potential was negatively moved, and meanwhile the oxidation peak current decreased apparently to the concentration of protionamide and then a new method for the protionamide determination was established. The linear equation between the decreasing current $(\Delta \mathrm{ip})$ and protionamide concentration was got as $\Delta \mathrm{ip}(\mu \mathrm{A})=0.01514 C(\mathrm{mg} / \mathrm{L})$ $-0.01553(n=9 ; r=0.991)$ with the linear range of $10.0 \sim 50.0 \mathrm{mg} / \mathrm{L}$, and the detection limit $(3 \sigma)$ was got as $8.25 \mu \mathrm{g} / \mathrm{mL}$. The effects of coexisting substances on the determination were carefully investigated and the protionamide artificial and tablet samples were detected with satisfactory results.
\end{abstract}

\section{Introduction}

Protionamide (PTH) is a thioisonicotinamide derivative and the structure is shown in Figure 1. Owing to the effective therapeutic effect for mycobacteria, PTH is used as a common second-line anti-TB drug and is often prescribed in combination with other anti-TB drugs against treatment refractory lung tuberculosis in clinical treatment [1]. To the best of our knowledge, the number of analytical methods reported in the literature for PTH determination is very low and the papers are also about 20 years old. According to Chinese Pharmacopoeia, titration method is used for PTH determination, which suffers from low sensitivity [2]. A high-performance liquid chromatography method was proposed by $\mathrm{H}$. Bartels and R. Bartels [3], which could be used for the human serum samples after an intricate pretreatment. Because of the advantages of high sensitivity, wide linear range, and simple equipment, electrochemical method has been widely applied to investigate the large biological molecules $[4,5]$. In recent years, with the continuous development of electrochemical analysis technology and continuous broadening of the research scope, the study of drug analysis and quality control have aroused widespread concern [6,7]. Alizarin red S (ARS) is a kind of basic biological stain, which is often selected as the electrochemical probe for the research of biological molecular in the life sciences. For example, Zhang et al. proposed a voltammetric determination method for catechol using poly(alizarin red S)/ionic liquid film modified electrode as working electrode [8]. A colorimetric determination method for dothiepin hydrochloride in pharmaceutical formulations with alizarin red $\mathrm{S}$ as a chromogenic agent was established by Abdulrahman and Basavaiah [9]. We also developed a new method for lysozyme determination using alizarin red $\mathrm{S}$ as electrochemical probe by linear sweep voltammetry [10].

In this paper, the electrochemical behavior of ARS and its interaction with PTH were studied, and a new electrochemical method for PTH detection was established with ARS as an electrochemical probe.

\section{Experimental}

2.1. Apparatus and Chemicals. The electrochemical measurements were carried out on an EC 550 (Wuhan Gaossunion Technology Co., Ltd., China) and a three-electrode system 


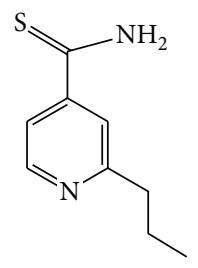

FIGURE 1: The chemical structure of protionamide.

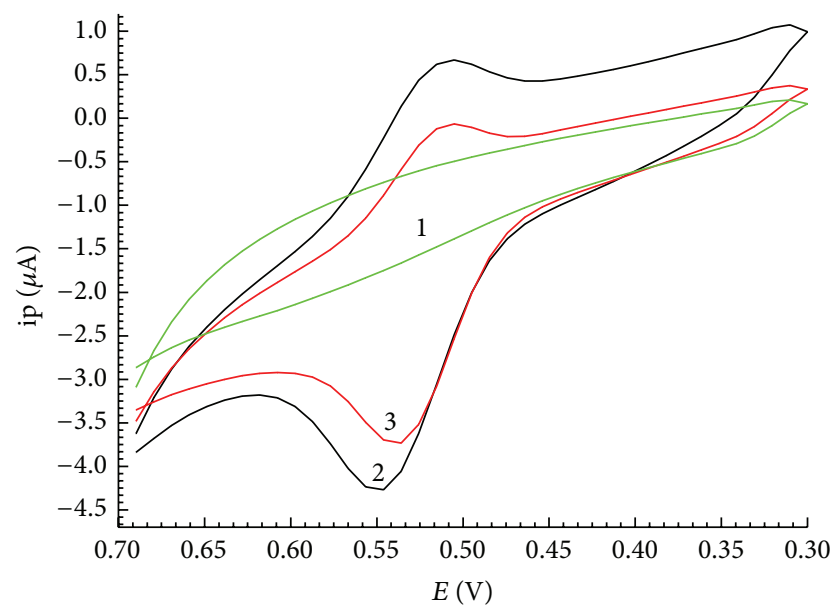

FIGURE 2: Cyclic voltammograms of ARS and ARS-PTH. Condition: 1.3.0 mL pH 5.0 PBS; $2.1+1.0 \times 10^{-5} \mathrm{~mol} / \mathrm{L}$ ARS; $3.2+30 \mathrm{mg} / \mathrm{L} \mathrm{PTH}$.

used in the measurements consists of a glassy carbon electrode as working electrode, $\mathrm{Pt}$ as counter electrode, and a saturated calomel electrode (SCE) as reference electrode. All potentials are given with respect to SCE. The pHS-25 meter (Shanghai LeiCi Instrumentation Co., Ltd., China) was used to measure the $\mathrm{pH}$ of the solutions.

Protionamide stock solution $(0.50 \mathrm{mg} / \mathrm{mL})$ was prepared by dissolving $0.0500 \mathrm{~g}$ of protionamide (Chembest Research Laboratories Co., Ltd., China) in ethanol and diluting to the mark in a $100 \mathrm{~mL}$ calibrated flask; then it was stored at $4^{\circ} \mathrm{C}$. The working solution was further diluted with ethanol. Alizarin red S solution $\left(1.0 \times 10^{-4} \mathrm{~mol} / \mathrm{L}\right)$ was prepared by dissolving $0.0360 \mathrm{~g}$ of alizarin red S (Tianjin Fu Chen Chemical Reagents Factory) in water and diluting to the mark in a $100 \mathrm{~mL}$ calibrated flask. $0.2 \mathrm{~mol} / \mathrm{L} \mathrm{HAc-NaAc}$ buffer solution was used to control the $\mathrm{pH}$ of the interaction solution. All other reagents were of analytical reagent grade and were used as received. Deionized water was used throughout this study.

2.2. Electrochemical Measurements. $0.20 \mathrm{~mL} 1.0 \times 10^{-3} \mathrm{~mol} / \mathrm{L}$ ARS solution, $5.0 \mathrm{~mL} \mathrm{pH} 5.0 \mathrm{HAc}-\mathrm{NaAc}$ buffer, and an appropriate amount of PTH (or samples) were added to a $10 \mathrm{~mL}$ volumetric flask in order. Then dilute the solution to the mark with water and mix thoroughly. After reacting at room temperature for $20 \mathrm{~min}$, the three-electrode system was immersed. The voltammetric responses were recorded in the range $+0.3 \mathrm{~V} \sim+0.7 \mathrm{~V}$ (versus $\mathrm{SCE}$ ) at $50 \mathrm{mV} / \mathrm{s}$. The reduction peak current of ARS at a potential of $+0.57 \mathrm{~V}$ (versus SCE) was recorded as the blank response ( $\left.\mathrm{ip}_{0}\right)$ and the peak current

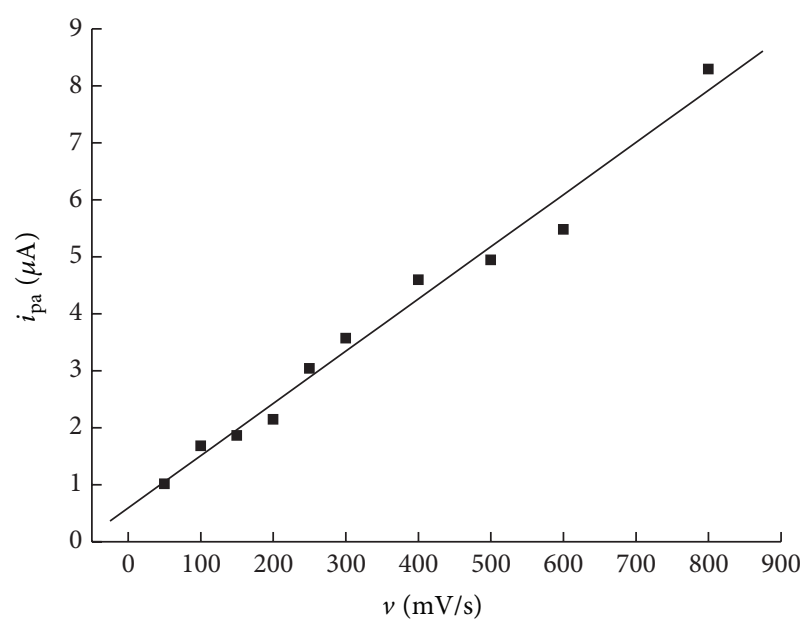

FIGURE 3: Relationship between $i_{\mathrm{pa}}$ and $v(\mathrm{mV} / \mathrm{s})$.

of the ARS-PTH complex was recorded as ip. The difference of the peak current $\left(\Delta \mathrm{ip}=\mathrm{ip}_{0}-\mathrm{ip}\right)$ was used for quantitative analysis. All the experiments were performed at $25 \pm 2^{\circ} \mathrm{C}$, except when otherwise stated.

\section{Results and Discussion}

3.1. The Cyclic Voltammograms of ARS-PTH Interaction System. The cyclic voltammograms of ARS at the bare GCE in $0.20 \mathrm{~mol} / \mathrm{L} \mathrm{pH} \mathrm{5.0} \mathrm{HAc-NaAc} \mathrm{buffer} \mathrm{solution} \mathrm{were} \mathrm{shown}$ in Figure 2. The results indicated that ARS had a pair of asymmetric redox peaks at 0.545 and $0.51 \mathrm{~V}$, respectively, and the $\Delta E_{p}$ was calculated as $35 \mathrm{mV}$. From Figure 2, it also can be seen that after the addition of PTH to ARS solution the peak current values of ARS decreased and the peak potential values moved negatively (curves 2 and 3 ).

Acidity experiments showed that the $\mathrm{pH}$ values of HAc$\mathrm{NaAc}$ buffer had significant effects on the electrochemical response of ARS. Over the range from pH 3.0 to 6.0, the oxidation peak potentials $\left(E_{\mathrm{pa}}\right)$ shifted negatively and with a linear regression equation of $E_{\mathrm{pa}}=0.821-0.058 \mathrm{pH}$. According to the equation of $E_{\mathrm{pa}}=E^{0}-(0.059 \mathrm{~m} / \mathrm{n}) \mathrm{pH}$ [11], we suggest that the same number of protons and electrons was involved in the electrochemical reaction.

The effects of scan rate $(v)$ on the peak current $\left(I_{\mathrm{pa}}\right)$ of ARS were further studied. The results displayed that the CV curves of ARS changed regularly with the increase of scan rate. As shown in Figure 3, the plots of oxidation peak currents had good linear relationship with the scan rate $(v)$ with regression equations of $i_{\text {pa }}(\mu \mathrm{A})=0.0092 v(\mathrm{mV} / \mathrm{s})+$ $0.59(r=0.993)$, suggesting that the electrochemical process of ARS was controlled by diffusion [12].

3.2. Optimal Conditions of General Procedure. The influences of acidity and the volume of HAc-NaAc buffer solution on the binding reaction of ARS with PTH were separately studied according to the difference of peak current of ARS before and after the addition of PTH (as $\Delta \mathrm{ip}$ ). The results were showed in Figure 4, which indicated that the value of $\Delta \mathrm{ip}$ reached 


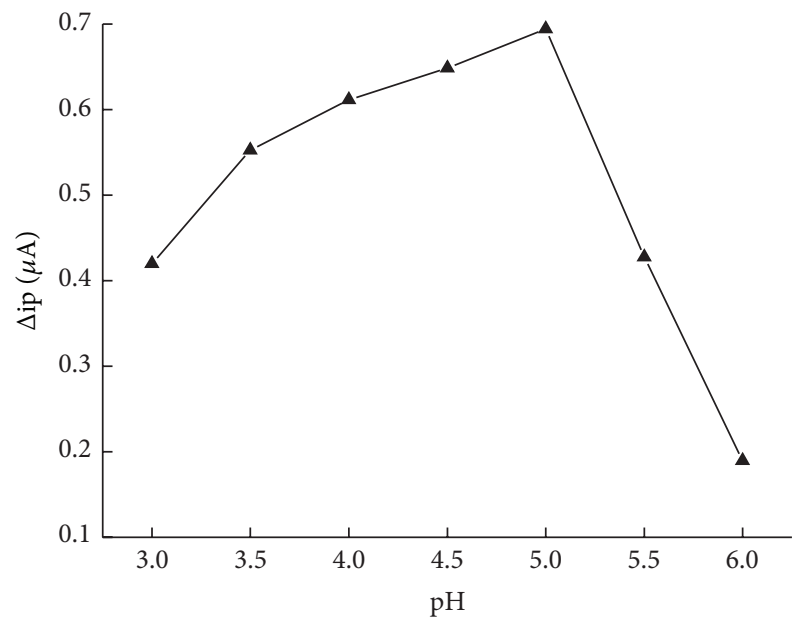

(a)

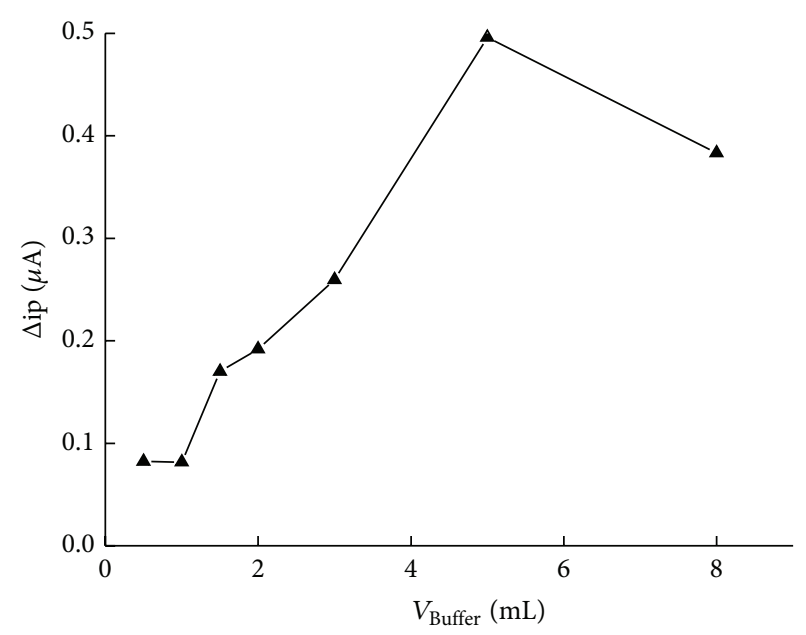

(b)

FIGURE 4: Effect of $\mathrm{pH}$ and the volume of buffer on the cyclic voltammograms of the interaction system.

maximum at $\mathrm{pH} 5.0$ (a) and the volume at $5 \mathrm{~mL}$ (b), so $\mathrm{pH}$ 5.0 and $5 \mathrm{~mL}$ were chosen for the assay.

The effect of ARS concentration on $\triangle$ ip value was studied with $20.0 \mathrm{mg} / \mathrm{L}$ PTH with the results showing that when the ARS concentration was at $1.0 \times 10^{-5} \mathrm{~mol} / \mathrm{L}, \Delta$ ip reached the maximum, so $1.0 \times 10^{-5} \mathrm{~mol} / \mathrm{L}$ ARS concentration was recommended in this paper.

The value of $\Delta \mathrm{ip}$ reached the maximum within $30 \mathrm{~min}$ and remained stable for at least 2 hours. Therefore, this system gave enough time for routine measurement. The effect of reaction temperature on the value of $\Delta \mathrm{ip}$ was tested at 15,25 , 30,35 , and $40^{\circ} \mathrm{C}$, respectively. The results indicated that there were no obvious differences among them, so $25^{\circ} \mathrm{C}$ was used throughout.

\section{Analytical Application}

4.1. Calibration Curve and Detection Limit. Under the optimal conditions, with ARS concentration at $1.0 \times 10^{-5} \mathrm{~mol} / \mathrm{L}$, a calibration curve for PTH determination was obtained using the $\Delta \mathrm{ip}$ value and PTH concentration in the range of 10.0 $50.0 \mathrm{mg} / \mathrm{L}$ with the linear regression equation as $\Delta \mathrm{ip}(\mu \mathrm{A})=$ $0.01514 C(\mathrm{mg} / \mathrm{L})-0.01553(n=9 ; r=0.991)$, which was showed in Figure 5. The relative standard deviation (RSD) for eleven parallel determinations of $30.0 \mathrm{mg} / \mathrm{L} \mathrm{LT}$ was $3.56 \%$ and the detection limit was calculated as $8.5 \mathrm{mg} / \mathrm{L}(3 \sigma)$.

4.2. Effect of Coexisting Substances. The effect of coexisting substances such as amino acids, glucose, and metal ions on the determination of $30.0 \mathrm{mg} / \mathrm{L}$ PTH was tested. As shown in Table 1, most of the cations and amino acids had little influences on the determination of PTH. But human serum albumin (HSA) showed obvious influence on the interaction, which may be caused by the absorption on the surface of electrode.

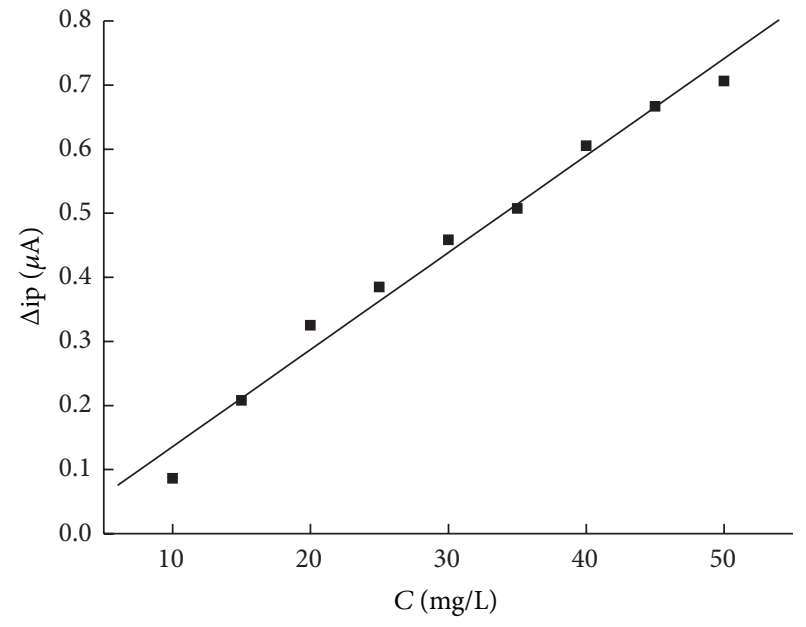

FIGURE 5: The working curve for the determination of PTH.

4.3. Sample Determination. Artificial protionamide samples containing metal ions, amino acids, and so forth were determined and the results are listed in Table 2. It can be seen that $y$-RNA in the artificial samples could be determined with satisfactory results and the recoveries were in the range of $102.7 \%-107.0 \%$, which indicates that this method is practical and reliable.

The proposed method was further applied to determine the compound protionamide tablet samples ( $0.1 \mathrm{~g}$ per tablet), which were purchased from Shanxi Taiyuan Jinyang Pharmaceutical Co., Ltd. (H14022093). The procedure for preparing protionamide sample solution was as follows: one piece of protionamide tablet was carefully ground in the agar, transferred to a $100 \mathrm{~mL}$ volumetric flask, and diluted to the scale. A $0.3 \mathrm{~mL}$ solution was further diluted with water in a $10 \mathrm{~mL}$ calibrated tube and then detected by the experimental 
TABLE 1: Effect of coexisting substances on the determination of $3.0 \mathrm{mg} / \mathrm{L} \mathrm{PTH}$.

\begin{tabular}{lccccc}
\hline Coexisting substances & $\begin{array}{c}\text { Concentration } \\
(\mathrm{mg} / \mathrm{L})\end{array}$ & Relative error (\%) & $\begin{array}{c}\text { Coexisting } \\
\text { substances }\end{array}$ & Concentration (mg/L) & Relative error (\%) \\
\hline Glucose & 5.0 & 3.49 & $\mathrm{Ca}^{2+}$ & 5.0 & 3.16 \\
L-Arginine & 5.0 & -2.78 & $\mathrm{Cu}^{2+}$ & 5.0 & 2.50 \\
L-Tyrosine & 5.0 & 2.95 & $\mathrm{Zn}^{2+}$ & 5.0 & -1.60 \\
L-Glutamic acid & 5.0 & 3.38 & $\mathrm{Mn}^{2+}$ & 5.0 & -2.58 \\
HSA & 5.0 & 5.72 & $\mathrm{Mg}^{2+}$ & 5.0 & -2.27 \\
\hline
\end{tabular}

TABLE 2: Results of the determination of PTH in synthetic samples $(n=5)$.

\begin{tabular}{lcccc}
\hline \multirow{2}{*}{ Sample } & Coexisting substances & \multicolumn{2}{c}{ PTH (mg/L) } & Found \\
\hline 1 & L-Arginine, L-tyrosine, glucose, and $\mathrm{Zn}^{2+}$ & 30.0 & 32.1 & 107.0 \\
2 & L-Tyrosine, L-glutamic acid, $\mathrm{Zn}^{2+}$, and $\mathrm{Cu}^{2+}$ & 30.0 & 30.8 & 102.7 \\
\hline
\end{tabular}

TABLE 3: Analysis results of protionamide content in protionamide tablet.

\begin{tabular}{|c|c|c|c|c|c|c|c|c|c|}
\hline \multirow{2}{*}{ Sample } & \multicolumn{5}{|c|}{ Single determination $(\mathrm{mg} / \mathrm{L})$} & \multirow{2}{*}{$\begin{array}{c}\text { Average } \\
(\mathrm{mg} / \mathrm{L})\end{array}$} & \multirow{2}{*}{$\begin{array}{c}\text { RSD } \\
\% \\
\end{array}$} & \multirow{2}{*}{$\begin{array}{c}\text { Specified } \\
(\mathrm{mg} / \mathrm{L})\end{array}$} & \multirow{2}{*}{$\begin{array}{c}\text { Recovery } \\
\%\end{array}$} \\
\hline & 1 & 2 & 3 & 4 & 5 & & & & \\
\hline H14022093 & 31.3 & 32.2 & 31.8 & 31.6 & 31.4 & 31.64 & 3.92 & 30.0 & 105.5 \\
\hline
\end{tabular}

procedure with the detection results shown in Table 3. The recovery was performed with the standard addition method to evaluate the accuracy of the method. It can be seen that the results were satisfactory.

\section{Conclusion}

The electrochemical behaviors of ARS and its interaction with protionamide were investigated by cyclic voltammetric method. Under the selected conditions, the oxidation peak current was proportional to protionamide concentration in the range from 10.0 to $50.0 \mathrm{mg} / \mathrm{L}$, and a novel voltammetric method for the determination of protionamide was developed with the detection limit as $8.25 \mathrm{mg} / \mathrm{L}(3 \sigma)$. The proposed method was further applied to protionamide artificial and tablet samples detection with high sensitivity, excellent reproducibility, and good stability.

\section{Conflict of Interests}

The authors declare that there is no conflict of interests regarding the publication of this paper.

\section{Acknowledgment}

This work received financial support from the project of Shandong Province Higher Educational Science and Technology Program, Shandong Province, China (nos. J11LB60 and J12LD62).

\section{References}

[1] Chinese Pharmacopoeia, vol. 2, China Medical Science Press, Beijing, China, 2010, (Chinese), http://www.drugfuture.com/ standard/search.aspx.

[2] F. Mühlberger, F. Nturanye, J. Nasbimana et al., "Ofloxacincycloserine-protionamide-INH combination against treatment refractory lung tuberculosis," Pneumologie, vol. 49, no. 2, pp. 72 76, 1995.

[3] H. Bartels and R. Bartels, "Simple, rapid and sensitive determination of protionamide in human serum by high-performance liquid chromatography," Journal of Chromatography B: Biomedical Applications, vol. 707, no. 1-2, pp. 338-341, 1998.

[4] W. Sun, Y. Q. Guo, Y. P. Lu et al., "Electrochemical biosensor based on graphene, $\mathrm{Mg}_{2} \mathrm{Al}$ layered double hydroxide and hemoglobin composite," Electrochimica Acta, vol. 91, pp. 130136, 2013.

[5] X. L. Niu, W. Sun, and K. Jiao, "Voltammetric determination of hyaluronic acid based on its interaction with phenosafranine," Russian Journal of Electrochemistry, vol. 45, no. 8, pp. 902-907, 2009.

[6] W. Sun, Y. Wang, S. Gong, Y. Cheng, F. Shi, and Z. Sun, "Application of poly(acridine orange) and graphene modifiedcarbon/ionic liquid paste electrode for the sensitive electrochemicaldetection of rutin," Electrochimica Acta, vol. 109, pp. 298-304, 2013.

[7] X. Niu, P. Zhang, W. Zhang, and W. Sun, "A new electrochemical method for the determination of chondroitin sulfate based on its supramolecular interaction with the cupferron-lead(II) complex," Journal of the Serbian Chemical Society, vol. 79, no. 2, pp. 199-209, 2014. 
[8] Q. Zhang, D. Pan, H. Zhang, H. Han, and Q. Kang, "Development of a poly(alizarin red S)/ionic liquid film modified electrode for voltammetric determination of catechol," Electrochimica Acta, vol. 133, pp. 23-29, 2014.

[9] S. A. M. Abdulrahman and K. Basavaiah, "Use of alizarin red $\mathrm{S}$ as a chromogenic agent for the colorimetric determination of dothiepin hydrochloride in pharmaceutical formulations," Journal of Saudi Chemical Society, vol. 18, no. 2, pp. 107-114, 2014.

[10] W. Sun, N. Zhao, X. Niu, Y. Wang, and K. Jiao, "Linear sweep voltammetric studies on the supramolecular complex of alizarin red S with lysozyme and determination of lysozyme," Journal of Chemical Sciences, vol. 121, no. 2, pp. 217-223, 2009.

[11] E. J. Laviron, "General expression of the linear potential sweep voltammogram in the case of diffusionless electrochemical systems," Journal of Electroanalytical Chemistry and Interfacial Electrochemistry, vol. 101, no. 1, pp. 19-28, 1979.

[12] A. J. Bard, Electrochemical Methods, John Wiley \& Sons, New York, NY, USA, 1980. 

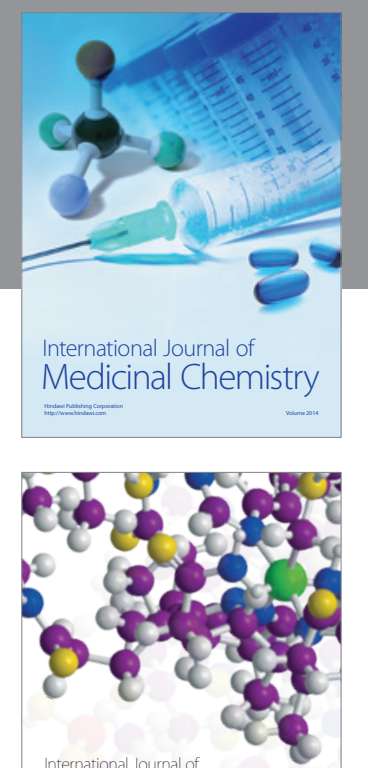

\section{Carbohydrate} Chemistry

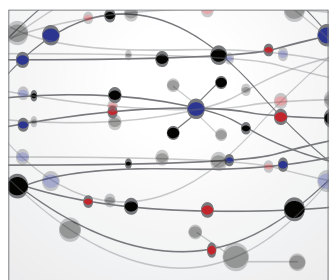

The Scientific World Journal
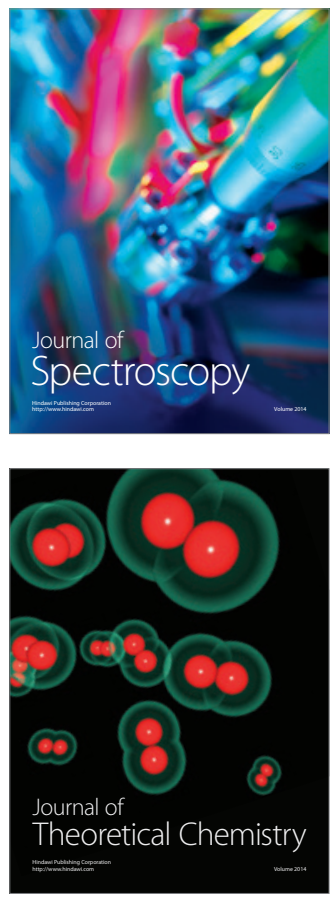
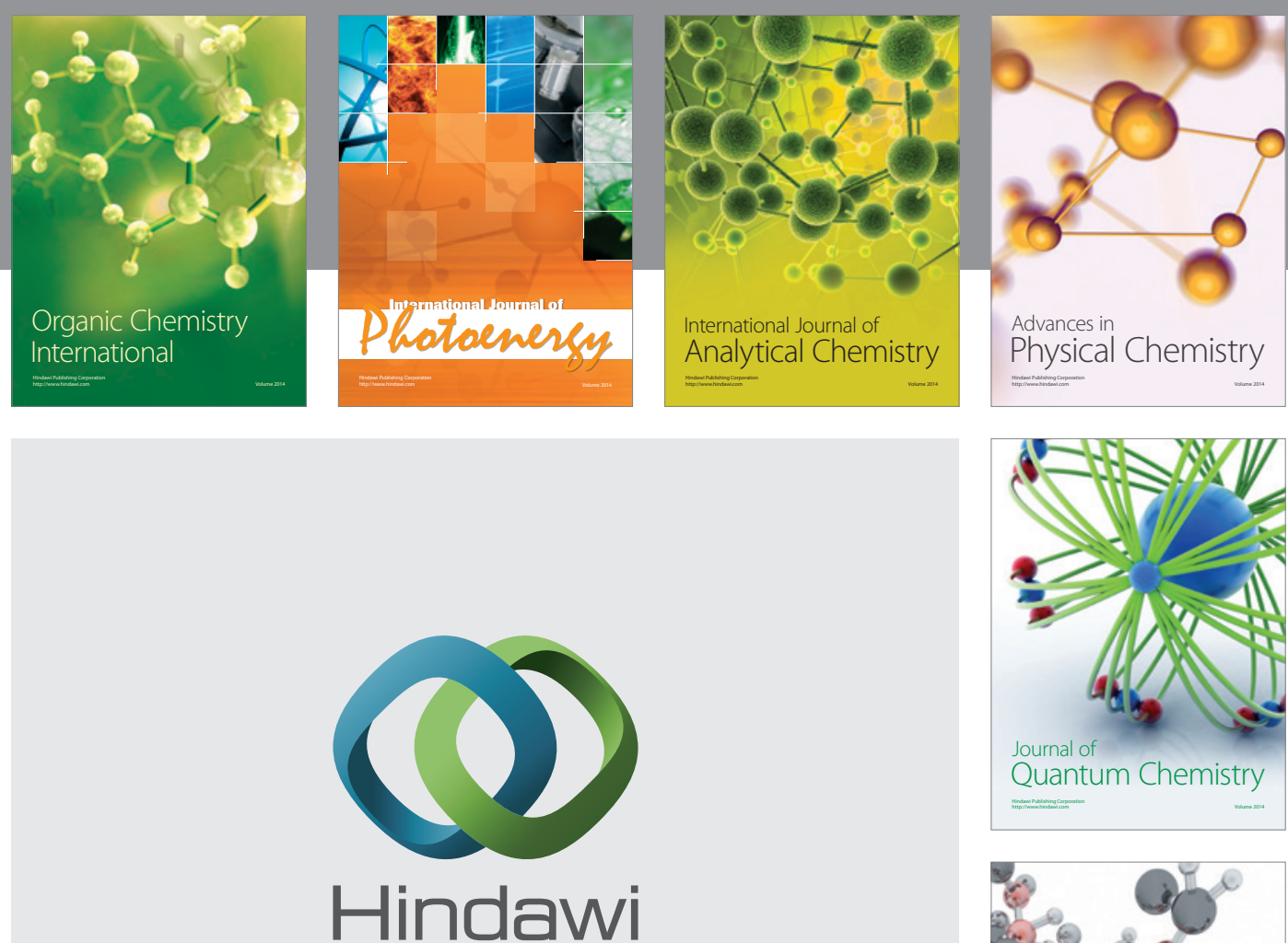

Submit your manuscripts at

http://www.hindawi.com

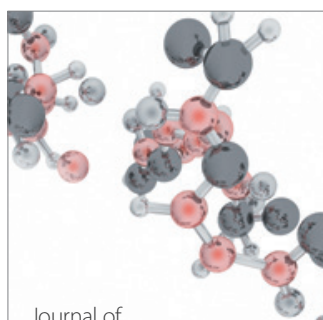

Analytical Methods

in Chemistry

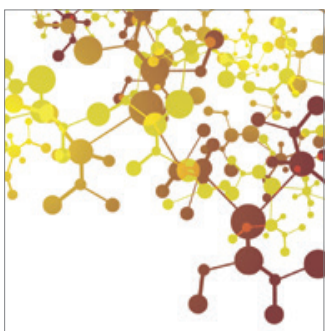

Journal of

Applied Chemistry

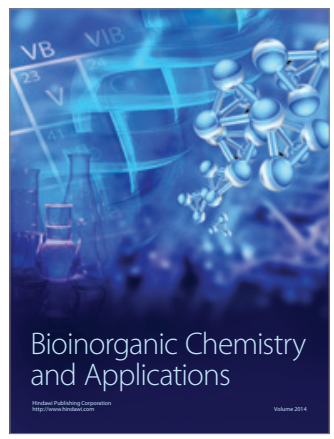

Inorganic Chemistry
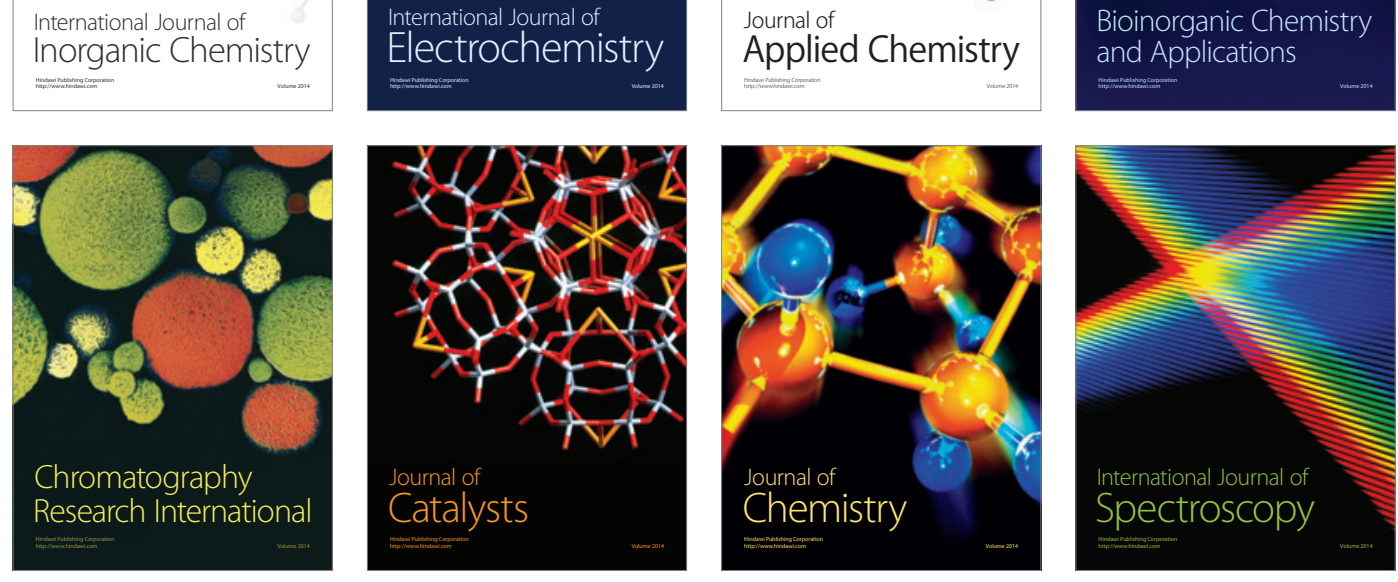